\title{
Exploring the role of the pastoral interpreter
}

Author:
Herculene Kotzé ${ }^{1}$
Affiliation:
'School of Languages, Faculty
of Humanities, North-West
University, South Africa
Corresponding author:
Herculene Kotzé,
herculene.kotze@nwu.ac.za
Dates:
Received: 21 Nov. 2017
Accepted: 14 Aug. 2018
Published: 15 Nov. 2018
code with your
mow to cite this article:
Kotzé, H., 2018, 'Exploring
the role of the pastoral
interpreter', HTS Teologiese
Studies/Theological Studies
74(2), a4873. https://doi.
org/10.4102/hts.v74i2.4873
Copyright:
Co 2018. The Authors.
Licensee: AOSIS. This work
is licensed under the
Creative Commons
Attribution License.

This article investigated the role of the pastoral interpreter within this contextually specific environment, taking cognisance of the debate regarding professional and non-professional interpreting and what this debate means for future research on interpreting role descriptions. Generally, pastoral interpreters in South Africa are untrained and not remunerated for their work as interpreters. Considering the foregoing, this investigation aimed to define the role of the pastoral interpreter in South Africa by using existing interpreting role models as a point of departure. The population of respondents involved in the study included all the freelance pastoral interpreters voluntarily working as interpreters at a Dutch Reformed Church in Pretoria, South Africa. Primary data collection took place in the form of (1) a structured selfadministered questionnaire and (2) a semi-structured focus group interview. The data were analysed using qualitative data analysis software, Atlas.ti. From the results of the study it can be deduced that pastoral interpreters' perception is that it would be unethical to not act according to what they believe in, and that is to deliver a message received from the Holy Spirit, thus becoming a spiritual conduit. The results of the study also indicated that formal training would enhance pastoral interpreting practices as there are gaps in untrained pastoral interpreters' theoretical knowledge and knowledge of standard interpreting practice.

\section{Introduction}

This article investigates the role of the pastoral interpreter within its contextually specific environment, taking cognisance of the debate regarding professional and non-professional interpreting and what this debate means for future research on role descriptions. Internationally, pastoral interpreters (also known as 'church' or 'religious interpreters'; Du Plessis 2017; Hild 2015) are known to work as facilitators in the church or religious environment. This environment offers a range of services from public service to intimate one-on-one counselling, but according to James (1998:16-17) church interpreting takes place in 'but a small percentage of all religious settings'. Research into pastoral interpreting is on the increase internationally and issues around the classification of interpreting domains, norms and performative structures, as well as sign language interpreting for the deaf, are among the topics that are being researched (cf. Hild 2015; 2016; Rayman 2007; Vigouroux 2010). According to Pöchhacker (2016:163), church interpreting has recently gained ground as an area of practice and research albeit mainly under the heading of non-professional interpreting. Locally, however - although the use of interpreting in religious settings is known to take place in South Africa - very little empirical research has been carried out and documented (Du Plessis 2017:32).

From an interpreting and interpreting training point of view, the fact that this type of interpreting is under-researched, in South Africa especially, prompted the investigation culminating in this article. Given the various research possibilities within the field of interpreting, the study had to be limited in terms of its focus and aims. In this regard, the focus of the study was to determine what role pastoral interpreters fulfil when interpreting a public service, and the aim was to compare this role fulfilment to existing interpreting role models and international findings on studies regarding interpreter roles. The contribution of this study is therefore twofold: First of all, it could contribute to our understanding of interpreting roles and role models, and secondly, it could serve as valuable information to pastoral interpreters and their understanding of the work that they do.

Generally, pastoral interpreters in South Africa are untrained and not remunerated for their work as interpreters. This is also true internationally - Hild (2015) states that interpreting in religious settings 'is usually performed by non-professional interpreters, untrained volunteers who are multilingual or bilingual and members of the worshipping community and who learn interpreting "on-the-job"'. The religious contexts and subcontexts in which they work often require of them to fulfil a role that cannot be defined by existing interpreting role models. If a definition of pastoral interpreting is to facilitate communication within a religious environment, then the question is,

Note: This article is published in the section Practical Theology of the Society for Practical Theology in South Africa. 
how can untrained interpreters fulfil the practice of pastoral interpreting without due consideration to the role they fulfil? Understanding what role it is that one is fulfilling is key when attempting to successfully interpret in any type of environment. How an interpreter perceives his or her role and how it manifests in reality is therefore crucial to defining the role of the interpreter.

Considering the preceding, this article aims to define the role of the pastoral interpreter in South Africa by using a recognised interpreting role model as a point of departure (Niska's role pyramid for community interpreters 2002:137138). In addition, it will offer recommendations as to how the role of the pastoral interpreter can be approached.

\section{The role of the interpreter: The professionalism debate}

Wadensjö (2011:13) states that although interpreting studies have developed quite substantially over the past decades, a lot of what has been done is centred on the so-called eternal questions, one of which is regarding the interpreter's role. Indeed, addressing the issue of the interpreter's role and role definitions is hardly new (Anderson 1978; 2002; Angelelli 2000; 2000b; 2003; 2004a; 2004b; 2006; Hale 2004; Hsieh 2006; 2007; 2008; Kotzé 2012; 2014; 2016; Mullamaa 2006; 2009). However, existing research regarding role descriptions and role fulfilment still leaves the question of what an interpreter is supposed to or not supposed to do. Furthermore, the topic of roles in interpreting has also become more complicated considering recent debates regarding professional versus non-professional interpreting (Fuehrer 2016; Moser-Mercer 2016; O'Hagan 2016; Schäffner 2016), and questions like 'What is a non-professional interpreter?' further obscure our view on role descriptions.

There is evidence (Angelelli 2000; 2003; Kotzé 2012; 2014; Mullamaa 2006; 2009) that the setting in which interpreting takes place has a discernible influence on how interpreters perceive their role and choose to fulfil their role in practice. This is echoed by Aguilar-Solano (2015:134), who argues that veiled social structures '[...] allow for the establishment of contextually specific positions for interpreters that may not exist elsewhere'. If we accept this to be true, then different types of interpreting should have different role models.

As regards pastoral interpreting, very little research is available on specifically the pastoral interpreter and virtually none on pastoral interpreter roles. 'Pastoral interpreting' here refers to the larger context of voluntary, unpaid interpreting within a religious environment (for instance, during a service rendered at any type of church), but also includes a number of subcontexts that are all related to religious service delivery. These services can range from interpreting during a funeral, during pastoral counselling, when visiting the ill or grieving or while spiritually supporting members of a congregation, to name but a few. These subcontexts may very well change because of the fact that churches, belief systems and religious traditions vary greatly. Each of these subcontexts differ from the last, which means that the role the pastoral interpreter fulfils is very complex.

The role of the pastoral interpreter becomes even more problematic in light of the fact that professional bodies and institutions require of professional interpreters to adhere to codes of ethics and practice standards within any interpreting event (AIIC 2009; CSHI 2008; IMIA 2007; SATI 2004). These codes of ethics and practice standards prescribe, to a certain extent, how an interpreter should approach and fulfil his or her role. However, underlying these prescriptions is the continuing support of the so-called channel role, which describes the interpreter as being an invisible 'machine' (Angelelli 2000a:582-590; 2000b:40-47; 2003:15-26; Tate \& Turner 1997; 2002:374; Wadensjö 1998:7).

However, when considering the role of non-professional interpreting, these prescriptions are of no importance, simply because non-professional interpreters are 'bilinguals without special training for the task' (Pöchhacker 2016:23) and therefore it cannot be expected or even assumed that these interpreters carry knowledge of codes of ethics or practice standards, much less adhere to them. A typical example here would be the pastoral interpreter, because of the fact that pastoral interpreters are more often than not untrained, unpaid and do not belong to professional interpreting bodies.

One can also ask whether being 'professional' is indeed required of an interpreter, to which most trained interpreters would probably say yes for various reasons. One of these reasons may very well be the extensive road interpreting training research has travelled and proved to be an essential part of being a successful interpreter (Class, Moser-Mercer \& Seeger 2004:507-512). However, what exactly does it mean to be 'professional'? Nicholson (2005:80) states that employing a trained and professional interpreter ensures that the interpreter will act according to accepted standards and procedures. Gile (1995:3) argues that training interpreters fulfils two important roles, one of which is to aid individuals to reach their potential as professional interpreters and to do so at an increased tempo. Corsellis (1999:198) further emphasises that training should focus on, among others, professional practice to prepare aspiring interpreters for the profession. According to Pöchhacker (2004:166) potential members of a profession must undergo a selection process and specialised training to ensure that they are able to adhere to prescribed and predetermined standards. In addition, Swabey and Mikkelson (2008:64) and Hale (2004) argue that a lack of training influences the interpreter's professional identity and add that interpreters with no training often feel unsure about their work, role, rights and responsibilities. Rosenberg, Seller and Leanza (2008:87) also conclude that professional interpreters' main aim is to ensure the transfer of information, versus family interpreters (untrained interpreters who are usually family members of those in need of interpreting), who mainly act as third participants, voicing their own views. Findings from research conducted in zones of crises and war (Moser-Mercer \& Bali 2007:403-404) indicated that 
interpreters are "often recruited because they "know" both the local language/dialect and English, the language of international relief operations, and not because they have been trained as translators or interpreters'. According to Moser-Mercer and Bali, this lack of training results in interpreters not being able to perform adequately as interpreters nor having the professional ethics to cope in such a stressful environment.

Although being 'trained' most probably is not the only requirement for being a professional interpreter, from the above one can deduce that having received interpreting training necessarily results in being recognised as a 'professional' interpreter.

In terms of what is expected of an interpreter, Toury (1995:55) states that repeated actions regarding the same type of behaviour can be of interest regarding norms in Translation Studies. In this regard, Toury (1999:25) argues that norms can be accepted as general values or ideas common to a specific group, for instance a group of interpreters. Norms act as a guideline in terms of what is right or wrong, acceptable or unacceptable, and act instructionally within specific situations.

When one adds to this what has been learned about training and professional behaviour in interpreting, the perceived challenge faced by the interpreter is to follow a prescriptive (channel) role description within an environment that may be unique in nature, for instance, the pastoral environment. The pastoral environment contains an element of the divine. Interpreters deliver a message sent by 'the Holy Spirit' (see discussion of data), which places them in a unique position where they have been 'called upon' to not only act as interpreters but as something unique.

There is evidence that suggests that the setting in which interpreting takes place has a significant influence on how interpreters perceive their role and choose to fulfil their role in practice (Angelelli 2000; 2003; Kotzé 2012; 2014; Mullamaa 2006; 2009). In addition, Angelelli (2003:16) states that very little research has yet been carried out on the perceptions that interpreters in particular have of their role and issues concerning it. This relates to Anderson's (2002:209) statement that perceptions may indeed influence role fulfilment, as well as Angelelli's (2004a:71) argument about different interpreting types having varied role approaches. Therefore, in order to determine what the role of the pastoral interpreter is, it is important to study the perceptions of role fulfilment within this environment, as these perceptions may have an influence on how pastoral interpreters fulfil their role.

In light of the foregoing, this article aims to investigate the role of the pastoral interpreter in the environment of a Dutch Reformed Church in Pretoria, South Africa. The study relates to interpreting that takes place within services held on Sundays and limited events offered by the church that take the same format as Sunday services. This data gives insight into how these pastoral interpreters perceive their role against the background of professional versus non- professional interpreting and sheds light onto how this environment contributes to the interpreters' perceptions of the role they fulfil.

\section{Ethical consideration}

Ethical approval to undertake the research was obtained from the North-West University (NWU) Institutional Research Ethics Regulatory Committee via the NWU Ethics Committee of Language Matters (Ethics number: NWU-00141-16-A8).

\section{Research design, data collection and findings \\ Research design and theoretical framework}

The research design followed in this study is a mixedmethods design; data were collected by means of a semistructured questionnaire and followed by a focus group interview in order to triangulate the data.

The theoretical model this study is based on is Niska's (2002:137-138) role pyramid for community interpreting. ${ }^{1}$ Niska contends that the community interpreter's role can be described as one of continuous involvement, depending on what the situation requires.

The shape of the model is indicative of the amount of time the interpreter supposedly spends fulfilling each role: for the most part they would act as a conduit, typically not adding, omitting or changing anything about the message and delivering it as accurately as possible. As one moves upwards on the model, the interpreter becomes more 'involved'. Acting as a clarifier, they would make changes to the message

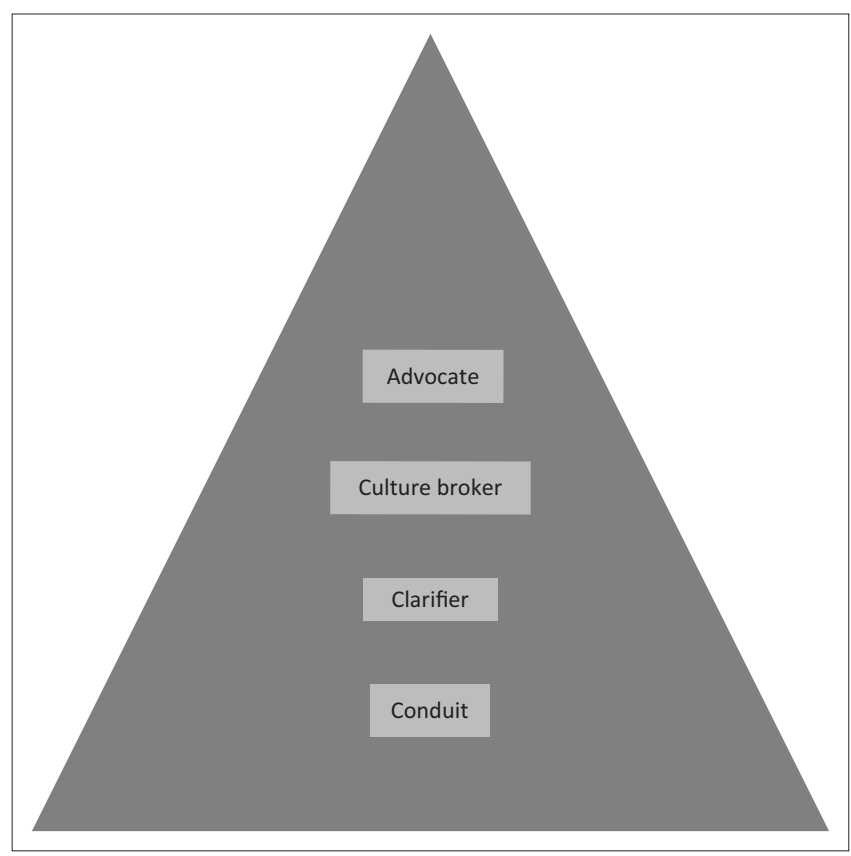

FIGURE 1: Niska's role pyramid for community interpreters.

1.Community interpreting, also known as 'public-service interpreting', refers to various institutional domains where public services are rendered (such as pastoral interpreting). 
to ensure the message is clear, whether it is by offering more information or giving an example, for instance. An even more involved role is that of culture broker, which entails that an interpreter would ensure that cultural bridges are crossed and that misunderstandings based on cultural differences do not occur. At the topmost level, fulfilling the role of advocate, the interpreter would act on behalf of the listener or user of the service, ensuring that they are not offended in any way.

What distinguishes Niska's role model from other role models is the possibility of an interpreter fulfilling several roles and doing so within any one interpreting event, depending on what is required and appropriate. This model was used to test the perception pastoral interpreters have of the role they fulfil and related role issues. This particular model was selected based on similar studies conducted on role definitions within community interpreting contexts where the role of the interpreter is unclear and/or unique (Kotzé 2014; 2016; Souza 2016). This model allows for the possibility that an interpreter fulfils not only one but several roles within a given interpreting situation, which reminds one of the role the pastoral interpreter fulfils within the larger context of pastoral interpreting. Because of the nature of the research question, both quantitative and qualitative data was collected in order to triangulate (Creswell 2009:174) the data and eliminate the possibility of subjectivity.

\section{Data collection}

The population of respondents involved in the study included all the freelance pastoral interpreters voluntarily working as interpreters at a Dutch Reformed church in Pretoria, South Africa. Some of these interpreters had received partial, informal training in the form of interpreting workshops offered by trained, qualified interpreter trainers, and only one had had formal interpreter training. In addition, these pastoral interpreters were voluntary, unpaid interpreters who believed themselves to have been 'called upon' to deliver a service, which positions them differently to other types of interpreting. The church council granted permission to conduct the study, as per ethical clearance requirements. The whole population of interpreters (14) were invited to take part in the study based on their availability and preference, of which 10 agreed to take part in the study. Respondents were each given an informed consent form, which offered details of the study and explained that they were taking part in the study on a voluntary and anonymous basis and could cease their participation at any point. They were also asked to sign this form as proof of their consent for the data to be used and published.

Primary data collection took place in the form of (1) a structured self-administered questionnaire ${ }^{2}$ and (2) a semistructured focus group interview; all 10 respondents took part in both, completing the questionnaire and taking part in the focus group interview. Both the questionnaire and interview took place at a venue made available by the church on a Saturday morning. Limited time was made available for data collection, which necessitated a focused interview that was carefully managed by the researcher.

In order to facilitate communication, it was agreed that respondents would answer questions in English, as everyone present were interpreters and understood English well enough to answer questions and engage comfortably. Although respondents were free to take their time to answer questions and ample time was made available for discussion, the researcher was careful to keep the discussion on the topic at hand.

Both a questionnaire and a focus group interview were conducted in order to allow the researcher to examine the topic from a qualitative and quantitative point of view, to triangulate the data, and in doing so validate the findings. The goal of the questionnaire was to determine which role (as described by Niska's [2002:137-138] role pyramid for community interpreting) the respondents identified with the most, and why. This was then compared to which role, based on the same model, they believed to be the correct role to fulfil as a pastoral interpreter. These findings were then used to inform the interview.

The data collected during the semi-structured interview and both the sound file and the transcription was coded inductively using Atlas.ti. In this regard, open coding techniques (axial coding and selective coding) were used (Greckhamer \& Koro-Ljungberg 2005:742), which, according to Strauss and Corbin (1990:12), entails comparing events, actions and interactions with similar phenomena in order to determine similarities or differences. The content of the interview was based largely on the trends identified during the analysis of the questionnaire, with the aim of gaining deeper insight into the role perceptions of the respondents. The aim of the questionnaire was twofold: to collect biographical data, and to collect perceptual data from the respondents by asking role-related questions based on Niska's role pyramid (2002:137-138).

Typical questions that were asked during the semi-structured focus group interview include:

- How do you perceive your role?

- What do you think your role as an interpreter entails?

- Are there things you believe an interpreter must do while interpreting? If so, what?

- Are there things you believe an interpreter should not do while interpreting? If so, what?

The last empirical phase was the interpretation phase, where data categories unfold and can be identified (also known as 'open coding'). These categories can then be measured or tested in terms of the theoretical model (known as 'axial coding') and the eventual indication of existing connections 
between the theoretical model and the data (known as 'selective coding'; Creswell 2009:191) takes place.

\section{Findings}

\section{Biographical information}

Of the 10 respondents, five were male and five female. Five of the respondents stated their age was older than 50 years, two between 40 and 49 years, one was between the ages of 30 and 39 and two said they were between 18 and 29 years of age (see Table 1).

The respondents were also asked to provide the number of years they had been active interpreters and which languages they usually interpreted into; this information is provided in Table 2 and Table 3.

\section{Role-related findings}

The questionnaire included two role-related questions, of which the first was: What do you think is the correct role for an interpreter to fulfil? The results of this question can be seen in Figure 2.

As is evident from Figure 2, four respondents selected both acting as a conduit and as a clarifier as the correct role to fulfil, three respondents selected a combination of conduit, clarifier and culture broker, and three selected being an advocate as the correct role to fulfil.

The respondents were also asked to clarify their answers on the previous question. To try and understand these results in

TABLE 1: Respondents' mother tongue.

\begin{tabular}{lc}
\hline Language(s) & Number \\
\hline Afrikaans & 4 \\
Afrikaans and English & 3 \\
Afrikaans and other & 1 \\
English & 1 \\
IsiNdebele, Setswana, Sesotho, Sepedi & 1 \\
\hline Total & $\mathbf{1 0}$ \\
\hline
\end{tabular}

TABLE 2: Years of experience of respondents.

\begin{tabular}{lc}
\hline Years & Number \\
\hline 0 years & 1 \\
1 year & 1 \\
6 years & 1 \\
7 years & 2 \\
10 years & 1 \\
13 years & 1 \\
14 years & 1 \\
\hline Total & 1 \\
\hline
\end{tabular}

Note: As is evident from Table 2, one respondent opted to not respond to this question.

TABLE 3: Languages respondents interpret into.

\begin{tabular}{lc}
\hline Language(s) & Number \\
\hline English & 4 \\
English and Afrikaans & 3 \\
English and Dutch & 1 \\
English and French & 1 \\
English and IsiZulu & 1 \\
\hline Total & $\mathbf{1 0}$ \\
\hline
\end{tabular}

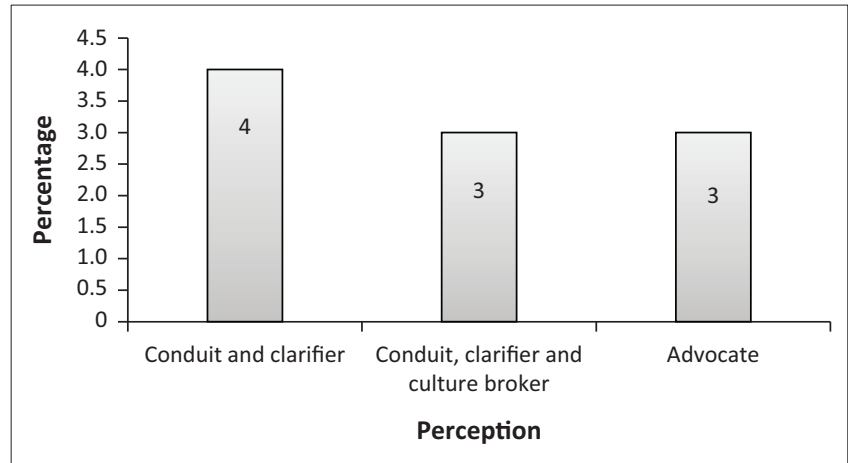

FIGURE 2: Respondents' perceptions of correct role to fulfil.

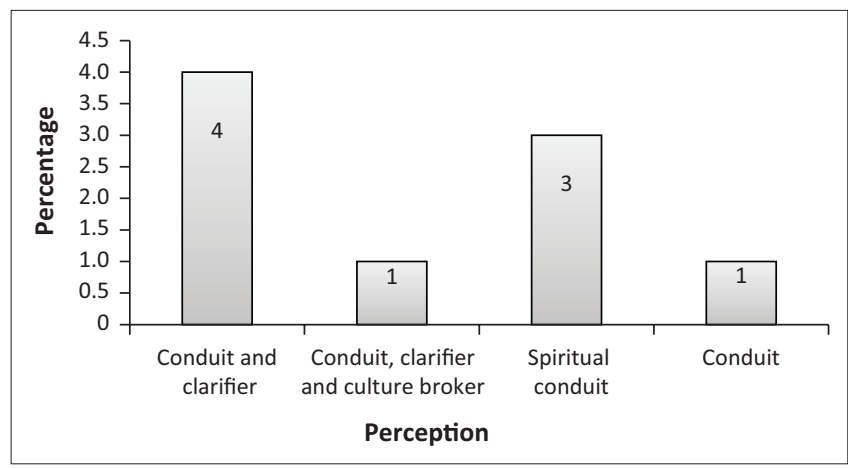

FIGURE 3: Respondents' perceptions of the role they fulfil.

Figure 2 better, the following statement (who had undergone interpreting training) gives some clarification:

'I would not so quickly get personally involved (Role D advocate), because I have been trained to only fulfil Role A (conduit). Over time I have learned to take on Role B and C (clarifier and culture broker), but to a limited extent. Role D (advocate) only afterwards, to try and ask the minister to speak more slowly at the next occasion.' (Respondent 4)

This statement shows that in terms of the training this interpreter had received, being taught to only fulfil the role of a conduit did influence the role this interpreter believed interpreters should fulfil. However, being in the pastoral environment has changed this viewpoint somewhat in that the interpreter does deem it necessary to act as a clarifier and/or culture broker at times. It also seems like fulfilling the role of an advocate only takes place after the interpreted event, and not during it, by asking the minister to speak slower during his next sermon.

The above results become truly insightful when compared to the results from the second question, which was: What role do you choose to fulfil while interpreting? See Figure 3 for the results.

In terms of Figure 3, only 9 of the 10 respondents answered the question. At first glance one can see that the respondents' selections in terms of their own role fulfilment does not completely correspond with their selections regarding what the correct role is to fulfil. Although four respondents also selected a combination of conduit and 
clarifier as the role they fulfilled during interpreting, only one respondent selected the combination of conduit, clarifier and culture broker as descriptive of their own role, in contrast with the four respondents who indicated that this would be the correct role to fulfil. In addition, three respondents offered the role of 'spiritual conduit' when describing the role they fulfil while interpreting, and one selected the role of advocate, although this was not one of the roles any of the respondents selected to be the correct role to fulfil.

These results can be better understood when again referring to the answers the respondents gave in terms of their responses on which role was correct to fulfil and the roles they chose to fulfil:

'It is very important to convey meaning and context of the message and retain the spiritual intent a guided by the Holy Spirit. It's all about salvation.' (Respondent 2)

This quote partially clarifies the discrepancy between Figure 2 and Figure 3. The foregoing statement by Respondent 2 highlights the possibility that pastoral interpreters indeed felt that a greater force was guiding them, and took their users' spirituality and the message they were delivering very seriously, because 'salvation' was at stake.

When read alongside the results from the qualitative analysis, the foregoing findings offer valuable insight into the role of the pastoral interpreter. Three themes were identified during the qualitative analysis phase: roles (based on Niska's role pyramid), role-related issues and the spiritual role of the pastoral interpreter.

Codes were identified based on these three themes and how the data related to the topic of role fulfilment. These three themes, as well as the codes identified as part of these themes, will be discussed next, taking cognisance of the quantitative findings.

\section{Qualitative data analysis: Theme 1 - Roles}

The qualitative data were analysed inductively regarding different themes, the first of which was the four roles that were used as the point of theoretical departure: conduit, clarifier, culture broker and advocate.

Clarifier: The code 'clarifier' was used to identify data that related to the interpreters acting as a clarifier - in other words, ensuring that the user understood the message by clarifying information. The following response offers a good description of what the role of the clarifier in the pastoral setting looks like:

'Uhm it's more, meaning plays a larger part so you have to add a bit to the sermon sometimes, when you're translating, because if you simply just translate the words exactly like they are spoken then you will miss some of the meanings and the feelings that the pastor likes to invoke. Like the ... So you kind of need to add at times.' (Respondent M4)
The role that is being described here relates closely to the next code that was identified, that of fulfilling the role of 'culture broker':

'I think there is also a portion of the culture broker where I come from an English Methodist background and when in Afrikaans they'd start talking about 'die kerkleer' and, and 'die ring' and, et cetera, et cetera. You do need to know and interpret that across experimentally speaking not necessarily used to Dutch Reformed church about what is actually being meant there, so you use, you would use synonyms, you would use them as circuit or etcetera. So, there is that form of, okay that's clarification but it is a bit of a bridge between $[\ldots]$ between the cultures that are represented.' (Culture broker)

Here Respondent M2 offers a very clear example of how, even within similar circumstances, clear distinctions are made between the different religious cultures and how they operate within isolated environments. This interpreter recognises the need for this cultural gap to be bridged and chooses to act as a culture broker within the English Methodist environment for members coming from a Dutch Reformed background.

Another code that reached saturation was 'advocate'.

Advocate: Advocating for the user means that an interpreter acts on behalf of the user, to ensure that the user is not offended in any way. Interestingly enough, advocacy in the pastoral environment takes on a different form from the educational interpreting environment, where interpreters would advocate on behalf of the user within the interpreted event (Kotzé 2014). From the following quote, one can see that this is not the case regarding pastoral interpreting:

'Advocacy, if I may come in there, when we get the opportunity to get all the ministers together and, and it takes a lot of organising to get that done and handing out to them our requirements and training them to make use of interpreting services [...].' (Respondent F3)

Advocacy in the pastoral environment therefore seems to take place outside of the interpreted event and takes the form of training and/or handing over a list of requirements from the interpreters.

Conduit: The code 'conduit' also reached saturation, but in a different manner than is conventionally known. The respondents used the term 'spiritual conduit' of their own accord. This term encompasses what they believed their (pastoral interpreter) role really entailed, and for this reason it is presented under 'Theme 3 -Spirituality of the pastoral interpreter'.

\section{Qualitative data analysis: Theme 2 - Role-related aspects}

The second theme the data yielded was role-related aspects, and two codes reached saturation: lack of interpreting knowledge and the importance of background knowledge.

Importance of background knowledge: The importance of background knowledge was touched on several times by different respondents. These pastoral interpreters seemed to 
firmly believe that having a good grasp of not only the message but also the pastor(s) and the environment of the church was very important in delivering a good interpreting product. This can be seen from the following quote:

'So uhm I believe a good sort of pastor or in that sense an interpreting background, means a lot. You are able then to do a little bit of clarification, uh, when it is specifically needed in an Afrikaans context.' (Respondent M2)

The fact that this interpreter stated that they 'trained' the ministers is also an interesting finding because most of these interpreters had not been professionally trained themselves, which also became known when the following code reached saturation.

Lack of interpreting knowledge: This code was used to identify instances of lack of interpreting knowledge. For instance, when one of the interpreters made a statement that contradicted conventional and popular interpreting practices, this code was employed. Here is an example of such a statement:

'I just wanted to ask that while you're busy interpreting like are you allowed to summarise some of the words, because Afrikaans and English they are not the same.'

This statement by Respondent F6 highlights the fact that, although the interpreters had had some training, this interpreter was not aware of the recognised practise of summarising or condensing information and the fact that this strategy is essential when working as an interpreter. This may be because the training they received was informal and only covered limited topics regarding interpreting practice. This also may be evidence that training is indeed required to act as a professional interpreter.

\section{Qualitative data analysis: Theme 3-Spirituality of the pastoral interpreter}

Figure 3 illustrates that during the quantitative data collection phase, three respondents added an additional role description to Niska's (2002:137-138) role pyramid. They did this to adequately describe the role they believed they fulfilled. They termed this role 'spiritual conduit'. To clarify this role, the qualitative data yield insightful information and are coded in terms of the theme 'the spiritual role of the pastoral interpreter'. Two codes that were identified reached saturation: spirituality of interpreters and spiritual conduit.

Spirituality of interpreters: This particular group of pastoral interpreters were all believers of the Gospel and they believed that you could not be a pastoral interpreter if you were not a believer. 'I think it would be very difficult for somebody who is not a believer to do what we're doing, because it is really not just the facts that we are trying to convey' (Respondent F4). They made mention also of praying before each service to be guided by the Holy Spirit and that the Holy Spirit would 'speak through them', as can be seen from this quote:

'We strongly believe that this a spiritual ministry in which we should be guided by uhm, uh, the Holy Spirit. We trust and believe that this is a world and we pray that the Lord will enable us to serve as comrades and really convey the message that we believe the minister prayed from God. Uh, for the congregation will then be obvious or the visitors in our case must probably, uh, which the message that they, he that the Lord entrusted to him.' (Respondent F1)

This viewpoint is clarified and reiterated in the following code, that of spiritual conduit.

Spiritual conduit: The following quote encompasses what this group of pastoral interpreters believed their role to be:

'Because to me it is important to convey the meaning and the context of the message but retain the spiritual intent that is guided through the Holy Spirit, because that paramount as meaning is produced I mean have to be accountable for what we are speaking, 'cause it might be the first time a person has ever heard the word of the Lord [...].' (Respondent F4)

This quote is evidence of pastoral interpreters believing the message they were delivering was one guided by the Holy Spirit and, as can be seen from previous quotes, this is something they take very seriously as there may be 'eternal ramifications' (Respondent F1). It is argued that the spirituality of the pastoral interpreter is what firstly defines the pastoral interpreter, and secondly what distinguishes it from other types of interpreting. It then follows that pastoral interpreters should in fact receive training, which takes this into account in order to best prepare pastoral interpreters for their task.

\section{Conclusion}

The role of the interpreter is one in which spirituality and professionalism become intertwined. Regarding the group of pastoral interpreters taking part in this study, it can be deduced that these interpreters' perception was that it would be unethical to not act according to what they believed in, and that was to deliver a message from the Holy Spirit. The results show that they would not change the content of the message knowingly, but did concede that sometimes it was necessary to act as clarifiers or culture brokers.

There is sufficient evidence to state that the role of pastoral interpreters is influenced by the environment in which they work, but not in the conventional way. Their decision (or 'calling') to become pastoral interpreters speaks to this, but also the nature of the content they interpreted was markedly spiritual. It is within this internal and external spirituality where the uniqueness of pastoral interpreting can be found and another dimension is added to the existing role descriptions: that of spiritual conduit. It is argued that the role of the pastoral interpreter is unique in nature and has, until now, not been adequately described. A spiritual conduit is an interpreter who has a firm belief in the Holy Spirit and believes him- or herself to be have been called upon to be a pastoral interpreter, believing that the product he or she delivers has been received from the Holy Spirit. This finding is supported by similar studies that concluded that pastoral interpreters viewed themselves as co-creators of the worship 
event and as being an instrument or messenger of the Word of God (Pöchhacker 2015:345; Salawi 2010:131).

The results of the study also indicate that formal training would enhance pastoral interpreting practices, as there are gaps in untrained pastoral interpreters' theoretical knowledge and knowledge of standard interpreting practice. It is therefore strongly recommended that pastoral interpreters undergo (even if not formal) interpreting training so as to enhance their skills and abilities to perform the task of pastoral interpreting successfully. In addition, in light of the interpreters' close connection to all the parties involved in the church environment, it is also recommended that similar training on the use of an interpreter is undertaken by said parties to fully harness the possibilities of interpreting.

In terms of further research, it would be valuable for this study to be replicated in other types of religious environments to learn whether those environments have similar results and whether the role definition for pastoral interpreting offered here can be applied across other religious environments.

\section{Acknowledgements Competing interests}

The author declares that she has no financial or personal relationships which may have inappropriately influenced her in writing this article.

\section{References}

Aguilar-Solano, M., 2015, 'Non-professional volunteer interpreting as an institutionalized' practice in healthcare: A study on interpreters' personal narratives', In Translation \& Interpreting 7(3), 132-148.

Alvstad, C., Hild, A. \& Tiselius, E. (eds.), 2011, Methods and strategies of process research, John Benjamins, Amsterdam/Philadelphia.

Anderson, R.B.W., 1978, 'Interpreter roles and interpretation situations: Cross-cutting typologies', in D. Gerver \& H.W. Sinaiko (eds.), Language interpretation and communication, pp. 217-230, Plenum Press, New York.

Anderson, R.B.W., 2002, 'Perspectives on the role of interpreter', in F. Pöchhacker \& M. Shlesinger (eds.), The interpreting studies reader, pp. 208-217, Routledge, London.

Angelelli, C.V., 2000a, 'Interpreting as a communicative event: A look through Hymes' lenses', Meta 45(4), 580-592. https://doi.org/10.7202/001891ar

Angelelli, C.V., 2000b, 'Interpreting pedagogy: A bridge long overdue', ATA chronicle (Translation Journal of the American Association of Translators) 29(11), 40-47.

Angelelli, C.V., 2003, 'The interpersonal role of the interpreter in cross-cultural communication: A survey of conference, court and medical interpreters in the US, Canada, and Mexico', in B. Louise, G.L. Bastin, I. Hemlin \& H. Clarke (eds.), The critical link 3: Interpreters in the community, pp. 15-26, John Benjamins Publishing.

Angelelli, C.V., 2004a, Revisiting the interpreter's role, John Benjamins, Amsterdam.

Angelelli, C.V., 2004b, Medical interpreting and cross-cultural communication, Cambridge University Press, Cambridge.

Angelelli, C.V., 2006, 'Validating professional standards and codes: Challenges and opportunities', Interpreting 8(2), 75-93. https://doi.org/10.1075/intp.8.2.04ang

Class, B., Moser-Mercer, B. \& Seeber, K., 2004, 'Blended learning for training interpreter trainers', in D. Remenyi, (ed.), 3rd European Conference on E-learning pp. 507-515, Academic Conferences Limited, Reading.

Corsellis, A., 1999, 'Training of public service interpreters', in M. Erasmus, L. Mathibela, E. Hertzog \& H. Antonissen (eds.), Liason interpreting in the community, pp. 197205, Van Schaik, Pretoria.

Creswell, J.W., 2009, Research design: Qualitative, quantitative and mixed methods approach, Sage, Thousand Oaks, CA.

Du Plessis, M., 2017, Church Interpreting in an Interdenominational Christian Contex in Urban Johannesburg, University of the Witwatersrand, Johannesburg. (Research Report: MA).

Fuehrer, U., 2016, 'ENPSIT Training \& Accreditation committee - 5-year plan 2016 2020', Paper presented at the Third International Conference on Non-Professional Interpreting and Translation, Winterthur, Switzerland, 5-7th May.
Gile, D., 1995, Basic concepts and models for interpreter and translator training, John Benjamins Publishing Company, Amsterdam.

Greckhamer, T. \& Koro-Ljungberg, M., 2005, 'The erosion of a method: Examples from grounded theory', International Journal of Qualitative Studies in Education 18, 729-750. https://doi.org/10.1080/09518390500298204

Hale, S., 2004, 'The interpreter's identity crisis', Paper presented at the first conference of the International Association for Translation and Intercultural Studies: Translation and the Construction of Identity, Seoul, South Korea, 11-14th August.

Hild, A., 2015, 'Religious settings', in F. Pöchhacker (ed.), Routledge encyclopedia of interpreting studies, pp. 344-345, Routledge, New York.

Hild, A., 2016, 'Constructing the profile of voluntary interpreters in religious settings', in R. Antonini, L. Cirillo, L. Rossato \& I. Toressi (eds.), Non-professional interpreting in institutional settings, pp. 177-194, John Benjamins, Amsterdam.

Hsieh, E., 2006, 'Conflicts in how interpreters manage their roles in provide rpatient interactions', Social Science \& Medicine 62(3), 721-730. https://doi.org/10.1016/j. socscimed.2005.06.029

Hsieh, E., 2007, 'Interpreters as co-diagnosticians: Overlapping roles and services between providers and interpreters', Social Science \& Medicine 64(4), 924-937. $\mathrm{https} / / /$ doi.org/10.1016/j.socscimed.2006.10.015

Hsieh, E., 2008, “'I am not a robot!” Interpreters' views of their roles in health care settings', Qualitative Health Research 18(10), 1367-1383. https://doi. org/10.1177/1049732308323840

International Association of Conference Interpreters (AIIC), 2009, Code of professional ethics, viewed 29 August 2016, from http://www.aiic.net/ViewPage.cfm/ article24.htm.

International Medical Interpreters Association (IMIA) \& Education Development Center, Inc., 2007, Medical interpreting standards of practice, viewed 29 August 2016, from http://www.imiaweb.org/standards/standards.asp

James, R., 1998, 'Me, A religious interpreter? No Way!', Views: A Monthly Publication of the Registry on Interpreters for the Deaf, Inc. 15(3), 16-17.

Kotzé, H., 2012, "n Ondersoek na die veranderlike rol van die opvoedkundige tolk', North-West University, Potchefstroom Campus, Potchefstroom. (Thesis - PhD.)

Kotzé, H., 2014, 'Educational interpreting: A dynamic role model', Stellenbosch Papers in Linguistics Plus 43, 127-145.

Kotzé, H., 2016, 'Die rolpersepsies van opvoedkundige tolke in Suid-Afrika', In Tydskrif vir Geesteswetenskappe 56(3), 780-794.

Moser-Mercer, B., 2014, 'MOOCs in fragile contexts', Proceedings of the European MOOC Stakeholder Summit 2014, Lausanne, Switzerland, February 10-12, 2014 pp. 114-121.

Moser-Mercer, B., 2016, 'Professionalizing the humanitarian sector: Covering the last mile', paper presented at the Third International Conference on Non-Professional Interpreting and Translation, Winterthur, Switzerland, 5-7th May.

Moser-Mercer, B. \& Bali, G., 2007, 'Interpreting in Zones of Crisis and War: Improving multilingual communication through collaborative virtual learning', Proceedings of the 2007 MIT LINC Conference: Technology-Enabled Education: A Catalyst for Positive Change, Amman, Jordan, U.A.E. October 28-30, pp. 403-418.

Mullamaa, K., 2006, 'Towards a dynamic role conception of liaison interpreters: An ethnographic study of self-descriptions of practising liaison interpreters in Estonia', PhD thesis, Tartu University Press, Estonia.

Mullamaa, K., 2009, 'Towards a dynamic role model of liaison interpreters: Selfdescriptions of practitioners in Estonia', New Voices in Translation Studies 5, 46-62.

Nicholson, N.S., 2005, 'Personality characteristics of interpreter trainees: The MyersBriggs type indicator', The Interpreters' Newsletter 13, 109-142.

Niska, H., 2002, 'Community interpreter training: Past, present, future', in G. Garzone \& M. Viezzi (eds.), Interpreting in the 21st century: Challenges and opportunities. Selected papers from the 1st Forli Conference on Interpreting Studies, November 9-11, 2000, John Benjamins, Philadelphia. pp. 133-144.

O'Hagan, M., 2016, 'Translation Studies 2.0 - how to study illegal and unethical translation in dynamic digital environments', Paper presented at the Third International Conference on Non-Professional Interpreting and Translation, Winterthur, Switzerland, 5-7th May.

Pöchhacker, F., 2004, Introducing interpreting studies, Routledge, London and New York.

Pöchhacker, F. (ed.), 2015, Routledge encyclopedia of interpreting studies, Routledge, London.

Pöchhacker, F., 2016, Introducing interpreting studies, Routledge, London and New York.

Rayman, J., 2007, 'Visions of equality: Translating power in a deaf sermonette', The Sign Language Translator and Interpreter 1(1), 73-114.

Rosenberg, E., Seller, R. \& Leanza, Y., 2008, 'Through interpreters' eyes: Comparing roles of professional and family interpreters', Patient and Education Counseling 70. 87-93. https://doi.org/10.1016/j.pec.2007.09.015

Salawi, A., 2010, 'Evaluation of interpretation during congregational services and public religious retreats in south-west Nigeria', Babel 56(2), 129-138. https://doi. org/10.1075/babel.56.2.03sal

Schäffner, C., 2016, 'Translation and journalism: Professional values and ethics', Paper presented at the Third International Conference on Non-Professional Interpreting and Translation, Winterthur, Switzerland, 5-7th May.

South African Translators' Institute, 2004, Code of ethics for individual members, viewed 29 August 2016, from http://translators.org.za/sati_cms/downloads/ dynamic/sati_ethics_individual_english.pdf

Souza, I., 2016, Intercultural mediation in Healthcare: From the professional medical interpreter's perspective, Xlibris, Bloomington. 
Strauss, A.L. \& Corbin, J., 1990, Basics of qualitative research: Grounded theory procedures and techniques, Sage, Newbury Park, CA.

Swabey, L. \& Mickelson, P.G., 2008, 'Role definition: A perspective on forty years of professionalism in sign language interpreting', in C. Valero-Garces \& A. Martin (eds.), Crossing borders in community interpreting: Definitions and dilemmas, $\mathrm{pp}$ 51-71, John Benjamins, Amsterdam.

Tate, G. \& Turner, H.G., 2002, 'The code and the culture: Sign language interpreting - in search of the new breed's ethics', in F. Pöchhacker \& M Schlesinger (eds.), The interpreting studies reader, pp. 373-383, Routledge, New York.

Toury, G., 1995, Descriptive translation studies and beyond, John Benjamins, Philadelphia, PA
Toury, G., 1999, 'A handful of paragraphs on "translation" and "norms"', in C. Schäffner (ed.), Translation and norms, pp. 9-31, Multilingual Matters, Clevedon.

Vigouroux, C., 2010, 'Double-mouthed discourse: Interpreting, framing and participant roles', Journal of Sociolinguistics 14(3), 341-369. https://doi. org/10.1111/j.1467-9841.2010.00448.x

Wadensjö, C., 1998, Interpreting as interaction, Longman, London.

Wadensjö, C., 2011, 'Interpreting in theory and practice: Reflections about an alleged gap', in C. Alvstad, A. Hild \& E. Tiselius (eds.), Methods and strategies of process research, pp. 13-21, John Benjamins, Amsterdam/ Philadelphia. 